5. Кондратьев Г.М., Дульнев Г.Н., Платунов Е.С., Ярышев Н.А. Прикладная физика: Теплообмен в приборостроении. СПб.: СПбГУ ИТМО, 2003. $560 \mathrm{c}$.

6. Peretiaka N., Boriak K., Vatrenko O. Improving the thermal method for assessing the technical condition of rolling bearings based on the heating rate criterion. Eastern-European Journal of Enterprise Technologies. № 5/1 (107). 2020. P. 118-126. DOI: https://doi.org/10.15587/17294061.2020.212540

DOI https://doi.org/10.30525/978-9934-26-046-9-25

\title{
SIMULATION OF PROCESSING WITH ABRASIVE SUBSTANCE OF ANGULAR RECTANGULAR WAVEGUIDE CHANNEL
}

\author{
Tryshyn P. R. \\ Postgraduate Student at the Department of Technologies \\ of Mechanical Engineering \\ National University «Zaporizhzhia Polytechnic» \\ Honchar N. V. \\ Ph.D., \\ Associate Professor at the Department of Technologies \\ of Mechanical Engineering \\ National University «Zaporizhzhia Polytechnic»

\section{Lahovskyi O. V.} \\ Student at the Department of Technologies of Mechanical Engineering \\ National University «Zaporizhzhia Polytechnic» \\ Zaporizhzhia, Ukraine
}

Rectangular waveguides with numerous bends and twists are applied in the S-range radars. There are two types of waveguide bends: smooth curves, which are made by bending the waveguide tube, and angular bends, which are made by welding or brazing sections of the waveguide tube. Angular ones are used more often, as they are more compact (Fig. 1). Waveguides are made from a thin-walled $(2.5 \mathrm{~mm})$ rectangular pipe, the material is aluminum or brass. 


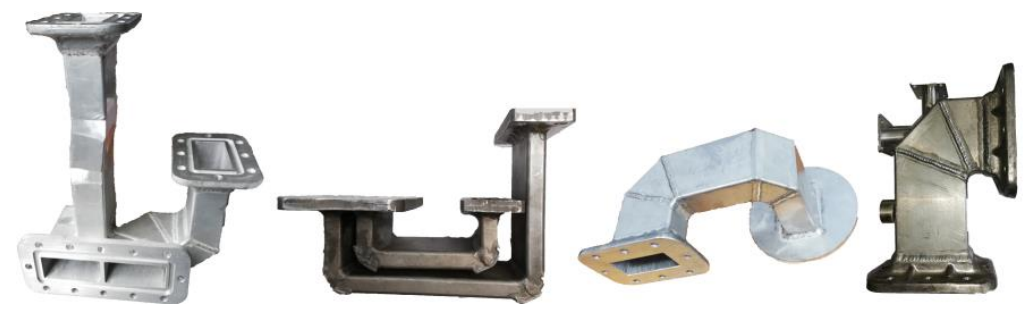

Figure 1. Rectangular waveguides with angular bends

During welding or brazing waveguide sections, deformations and surface defects appear in the seam zone. They are eliminated by planishing and subsequent finishing. The channel of the waveguides is polished with tight tolerances $(0.07 \ldots 0.1 \mathrm{~mm})$ and a roughness $\mathrm{Ra}<0.8 \mu \mathrm{m}$. The power loss of an electromagnetic wave depends on the quality of the surface of the channel [1, p.610].

Not all finishing methods which can provide the required roughness are applicable for channel rectangular section and angular bends. Often the polishing of the near-seam zones, due to the difficult approach to them, is carried out with a hand-held power tool, requires complex tool paths or the using of shaped tools.

Finishing of the waveguide channels of complex spatial shapes can be performed by methods which use the flow of an abrasive substance as a tool. This type of processing allows the mechanization of the operation, can improve working conditions and reduce processing time

The purpose of this study was to search for a rational finishing method with abrasive substance flow of channel angular bends of rectangular waveguide.

Hydro-abrasive (waterjet) pumping and abrasive-extrusion processing were studied.

Hydro-abrasive pumping [2] is an erosion process with a flow of waterjet processing for the inner surfaces. The waterjet slurry is pumped through the channel in both directions and creates a directional roughness.

The abrasive-extrusive processing of waveguides [3, p.41] consists in extrusion along the channel of the working substance, which composes from a polymer base with abrasive grains, which is capable of viscoelastic deformation.

The analysis of these methods for processing of channels with angular bends showed that the quality of the processed surface is often non-uniform 
due to significant changes in the parameters of the flow of the working substance.

Simulation of waterjet pumping and abrasive-extrusion processing of angular bends of waveguides was carried out using the software «Flow Vision» (Fig. 2). It showed the causes of irregular erosion within the channel. The flow of the working substance flowed around the inner corner and a vortex zone arose due to a sharp change in the direction of the walls. In this zone the pressure on the channel walls dramatically decreased, as a consequence, the intensity of processing of nearby surfaces reduced (Fig. 2a). A significant difference of abrasive-extrusion processing is the high pressure of the working substance on the channel walls and the low flow rate, which is associated with the higher viscosity of the working substance (Fig. 2b).

Between the transit flow and the swirl zone, the divide line appeared. It separated fluxes of different velocities and was a sign of local resistance. Separate vortices were formed at the divide line and moved continuously. In this case, some masses of the working substance in the swirl zone were replaced by others.

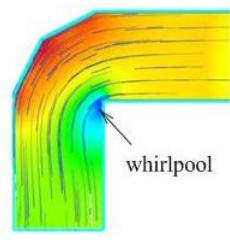

a

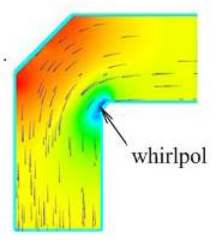

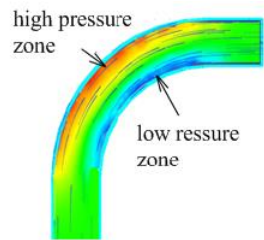

c

Figure 2. Simulation of hydro-abrasive pumping (a, c) and abrasive-extrusive processing (b) in the angler waveguide bends

When processing waveguides with a smooth channel bend (Fig. 2c), swirl zones don't appear, but centrifugal forces arise, which increase the pressure of the working substance on the walls with a large radius of curvature and decrease on the opposite walls. As a result, conditions are created for the movement of particles of the working substance in the transverse direction from the area of higher pressure to the area of lower pressure, which causes turbulence flow. After a smooth turn of the waveguide channel, a rotational-translational movement of the working substance emerges, which fades away at a certain distance. 
The disadvantages of the such methods of abrasive processing, which reduce the efficiency of their application for rectangular S-band waveguides with angular bends, include: limited flow control capabilities; uncontrolled removal of metal, which does not allow accurately processed surface; the need to prevent deformation of thin walls during extrusion of the abrasive substance through channel; applicability only for straight waveguides or smooth bends; the need to wash the treated surfaces. As a result, it was concluded that these finishing methods are time-consuming and inefficient for the rectangular waveguide channels with angular bends.

\section{References:}

1. Chen J., Binke H. Effects of surface roughness on lossy rectangular waveguide. Applied Computational Electromagnetics Society Journal. 2012. Vol. 27. № 7. P. 610-619.

2. Hydro-abrasive pumping URL: http://vaporblast.ru/projects/gidroabrazivnaya-prokachka/ (accessed 08.03.2021).

3. Sysoeva L. P. Abrasive extrusion processing of aluminum alloys. Vestnik SUSU (South Ural State University). 2015. Vol. 15. № 2. P. 40-50. 